\title{
MITO Y REALIDAD DE UNA ÉPOCA CRUCIAL (Tres publicaciones fundamentales en torno a la Guerra de Independencia)
}

\author{
Por Cayetano MAS GALVAÑ
}

Siempre resulta grato comunicar la aparición de publicaciones que estudian y abren nuevas perspectivas sobre problemas históricos insuficientemente conocidos o mal planteados. Pero si tales problemas no son otros que los relativos al período de la Guerra de Independencia, y las obras reseñadas son fruto de la colaboración entre un numeroso grupo de especialistas franceses y españoles, ya no cabe menos que felicitarse.

Este es el caso el Coloquio Internacional sobre Les Espagnols et Napoleon y de las mesas redondas sobre El clero afrancesado y Tres figuras del clero afrancesado (D. Félix Amat, D. Vicente Román Gómez, y D. Ramón José de Arce), que tuvieron lugar en Aix-en-Provence, respectivamente, en octubre de 1983, enero de 1985 y abril de 1986, cuyas actas han sido publicadas en la serie Etudes hispaniques de la Universidad de Provenza ${ }^{(1)}$. Son tres destacados jalones en la intensa actividad que en los últimos años viene desarrollando el Centre Aixois de Recherches hispaniques, a iniciativa, fundamentalmente, de los profesores Gérard Dufour y Guy Mercadier.

Nadie que se acerque a esta época con actitud rigurosa y desapasionada podrá soslayar las deficiencias con que ha sido tratada. No sólo la propia Guerra, sino también los años que la preceden y que inmediatamente la siguen. $Y$ más aún si se penetra en dominios como el de la actitud del clero ante la guerra y el régimen josefino. Es decir, que en gran medida, los reinados de Carlos IV y Fernando VII - sobre todo en la vertiente ideológico-cultural- siguen constituyendo todo un gran mundo por recorrer con nuevos ojos. Los trabajos aparecidos en los últimos años, honrosas excepciones presentes en la mente de todos, así lo han puesto de manifiesto. Las causas de tal pobreza historiográfica (cualitativa mucho más que cuantitativa), aparte la propia complejidad que de por sí presenta la lenta y convulsa agonía del Antiguo Régimen español, son bien evidentes. 
Y es que -digamos «historia viva obliga»-, pocas épocas han sido objeto de mayor controversia y mistificación. El juicio sumario, la simplificación maniquea y la deformación interesada, repetidos una y otra vez sin ir respaldados por investigaciones profundamente documentadas, fueron moneda corriente entre los autores que se ocuparon de estos años. Tales manipulaciones, que en lo ideológico se extendían hacia la Ilustración, partían tanto de los liberales como de los reaccionarios. Pero no cabe duda que el discurso de estos últimos se impuso sin discusión en España con una vitalidad que ha alcanzado nuestros propios días. Entre sus aspectos, destacaremos, por cuanto hace a lo que nos interesa ahora, su insistencia en la tesis del complot exterior. En ella, Francia es presentada como la gran culpable de las desdichas de los españoles. Primero invadió nuestra cultura y corrompió a nuestros dirigentes, sembrando la semilla del funesto liberalismo. No contenta con ello, pretendió después eliminarnos físicamente como pueblo por la vía de la invasión militar. Napoleón, en este caso, no era otra cosa que el Ángel del Abismo, la personificación del mal que nos ofrecía la fruta prohibida por mano de su hermano José y de los traidores «afrancesados». Ante ellos, el buen pueblo español, sin entrar en novedades ni en distingos ideológicos y acaudillado por sus dirigentes naturales, dio generosamente su sangre en favor del restablecimiento, en su posesión multisecular, del Altar y del Trono.

Colocadas las cosas en el plano de la pura mitificación, los acontecimientos históricos y sus protagonistas fundamentales pierden su relación con la objetividad histórica y se ven cargados de un valor simbólico que les viene dado por las exigencias del discurso ideológico en el que se integran . En consecuencia, las imágenes que se transmiten resisten mal un análisis profundo de su pretendida objetividad e informan ante todo de las concepciones de quien las emite.

Esta aproximación metodológica ha sido aplicada en profundidad en el coloquio de 1983. Plantear una cuestión en los términos en se ha verificado supone efectuar una inversión en su tratamiento habitual: Napoleón y España. Al menos, respecto de lo que era normal entre los historiadores franceses, pues los españoles bien poco añadían a los esquemas heredados de los absolutistas. Pero además del cambio de perspectiva, centrarse en los españoles y Napoleón permite extender ampliamente tanto los limites cronológicos como los propios horizontes temáticos. Así, cabe distinguir en este coloquio, a nuestro juicio, dos grandes grupos de comunicaciones de cuya conjunción, lejos de rompérse la deseable homogeneidad, resulta una doble aproximación perfectamente complementada.

En el primero de estos grupos se analiza a fondo el mito y la imagen napoleónica en España, su origen, naturaleza, evolución y connotaciones. Podemos encontrar en estas aportaciones tanto reflexiones metodológicas y sugestivos panoramas de conjunto, como análisis puntuales de lo que Napoleón (y todo cuanto representaba), supuso para los españoles del siglo XIX e incluso del actual. Es decir, se estudia la imagen napoleónica tal como se nos presenta en distintos medios, desde testimonios poco conocidos de los contemporáneos hasta alcanzar incluso el cine del franquismo, pasando por la literatura decimonónica. La cali- 
dad de cada una de las aportaciones y la necesaria brevedad de esta nota nos impiden destacar aquí otra cosa que parte del precipitado final de todas estas comunicaciones. Así, queda claro que el mito de Napoleón nos informa ante todo del conflicto interno y de los avatares ideológicos seguidos por los españoles, durante y después de la guerra. Ya en el transcurso de ella se configuraron las posturas básicas que se detectan más tarde. A la comprobación (en extremo sugerente) de que debe negarse la existencia de un punto de acuerdo en el principio nacionalista frente a Napoleón entre liberales y serviles, cabe sumar el papel de contrapunto, de contraste, que la imagen del corso desempeñó en el seño de cada discurso ideológico. Los liberales, interesados en la afirmación del concepto de nación, opondrán éste al de Napoleón casi únicamente en los años más duros de la lucha, antes de que otros problemas, como el de las colonias americanas, reclamen su atención y les hagan olvidar prácticamente al odiado invasor. En cuanto a los absolutistas, Napoleón les brindará una magnífica coartada en la que apoyarse para el rechazo de toda innovación y la defensa del tambaleante edificio del AntiguoRégimen.

A medida que la burguesía perdía, durante el siglo XIX, sus ímpetus revolucionarios, fue tomando cuerpo una leyenda napoleónica en la que su protagonista era ya ante todo símbolo de orden y progreso. El reaccionarismo, por su parte, no dejó de referirse al Emperador, a la Guerra y a Francia más que como medio para enaltecer las virtudes propias sobre el repudio de lo ajeno. En suma, la imagen napoleónica observada a lo largo del tiempo da cuenta, como pocas pueden hacerlo, tanto de la hegemonía del ultraconservadurismo en España como de la dramática debilidad del liberalismo progresista.

El segundo grupo de comunicaciones se centra en el análisis de parcelas históricas desconocidas o defectuosamente tratadas. La masonería bonapartista española, los problemas comerciales y los agobios fiscales de la guerra, las cuestiones del colaboracionismo y el afrancesamiento, la propia prensa afrancesada, los intentos franceses por captar la adhesión de nuestras propias colonias americanas, el carácter de los movimientos populares producidos en el curso de la Guerra e incluso el análisis de los motivos profundos que llevaron a los españoles a tomar las armas contra Napoleón (imprescindible leer esta comunicación como excelente antídoto contra las sublimaciones históricas)... tales son, entre otras, algunas de las cuestiones tratadas con nueva luz en este coloquio. Y en concreto este grupo de aportaciones viene a dejar bien claro hasta qué punto es preciso romper con los juicios apriorísticos recibidos y abordar el cúmulo de estudios pendientes de realizar en torno a la Guerra de Independencia ${ }^{(2)}$.

Precisamente parte de éstos deben dirigirse sin excusa al problema del «afrancesamiento». Y si a nivel general el conocimiento que de él disponemos dista aún mucho de alcanzar las cotas deseables, nuestra ignorancia se acentúa al descender al análisis de su intensidad y carácter entre cada estamento y grupo social. Muy en especial, en cuanto al clero se refiere. Una vez más el peso de la ideología reaccionaria se ha dejado notar con toda su fuerza. Resultaba ciertamente inconcebi- 
ble que el clero, depósito y garante de lo más profundo y entrañable del ser hispánico, pudiera llegar a «afrancesarse». A lo sumo, sólo eran admisibles unos pocos casos de resentidos, una simple gota de agua en la inmensidad del océano. De ahí que el mérito del profesor Dufour sea doble en este sentido. De un lado, como especialista en los temas del liberalismo cristiano (sus estudios sobre la figura de J. A. Llorente resulta de inexcusable lectura), su reflexión personal le condujo a romper con lo que él mismo denomina enfoque aislacionista en la cuestión del clero afrancesado. Ya no se trata, pues, de estudiar unos pocos casos aislados. Antes bien, nos encontramos ante un verdadero grupo de cléritos afrancesados, en su mayoría emigrados a Francia al finalizar la guerra, que evolucionaron hacia el liberalismo cristiano y desempeñaron más tarde un papel de gran peso en este sentido de la España del Trienio Liberal. La convergencia con los que habían sido liberales en Cádiz, gestada en los años del exilio posterior a 1814, era de esperar. Ambos, afrancesados y patriotas, compartían la extraordinaria preocupación heredada de la llustración española por la reforma de la espiritualidad y la estructura eclesiástica española, sinceramente sentida. Razones de táctica política e incluso de pura circunstancia personal les habían separado durante los años de la guerra, pero el fondo ideológico era el mismo. A la vista de ello, el lector juzgará cuán difícil se hace hablar aquí de traiciones o de heterodoxias.

De otro lado, es también mérito del profesor Dufour, consciente de la necesidad de reunir a los investigadores en asunto tan poco trillado, el haber organizado las dos mesas redondas de 1985 y 1986. En la primera, se estudiaron los intentos de reforma del clero tanto de la parte patriota-liberal como de la afrancesada entre 1808 y 1814 (en un estudio comparativo que de por sí ya justificaría todo el volumen), la mentalidad del clero afrancesado y colaboracionista, el clero afrancesado francmasón, y las peripecias seguidas por estos clérigos afrancesados en el exilio francés que se vieron obligados a emprender. Extensas listas y abundante información acerca de la nómina de estos personajes acompañan a casi todas las colaboraciones, lo que les presta una utilidad extraordinaria de cara a la realización de futuras investigaciones. En suma, este volumen viene a confirmarnos la importancia cuantitativa y cualitativa de un problema hasta ahora casi ignorado ${ }^{(3)}$. En cuanto a la segunda mesa redonda, del planteamiento general de la primera se desciende al análisis de tres figuras concretas y muy significativas: el obispo D. Félix Amat, el canónigo de Segovia D. Vicente Román Gómez y el que fuera Inquisidor General, D. Ramón José de Arce. Tres detallados estudios biográficos en los que sobre el problema común del afrancesamiento clerical, se mide en cada caso el grado que éste presenta y se pone de relieve la necesidad de descender al estudio del peso que las circunstancias personales tuvieron en cada uno de ellos ${ }^{(4)}$.

Aunque éstas son por el momento las publicaciones a las que ha dado lugar la actividad del Centre Aixois de Recherches Hispaniques, no puedo terminar esta breve reseña sin mencionar la que acaba de producirse y que, por el momento, viene a servir de señero colofón. Me refiero al Coloquio Internacional celebrado en la misma Universidad en noviembre de 1987 sobre Liberalismo cristiano y ca- 
tolicismo liberal en España, Francia e Italia. En ella, con la colaboración de las U. E. R. de Italiano y la asistencia de más de veinte especialistas de los tres países citados, se aborda una amplia problemática, central en el siglo XIX por cuanto se sitúa en un cruce ideológico tan importante como lo es el de la religión y la política. Y por cuanto se refiere a España, se ha puesto de manifiesto la existencia de una corriente (la católica liberal) que hasta ahora ha venido siendo negada con insistencia, o reducida a una dimensión episódica y aislada. Esperamos y deseamos la rápida publicación de las actas de este Coloquio.

\section{NOTAS}

(1) Les Espagnols et Napoleon (Actes du Colloque International d'Aix-en-Provence, 13-14-15 Octobre 1983) Publications Université Provence, Etudes Hispaniques, n. ${ }^{\circ} 7,1984$; El clero afrancesado (Actas de la mesa redonda, Aix-en-Provence, 25 enero 1985), Etudes Hispaniques, n. ${ }^{\circ} 10,1986 ;$ Tres figuras del clero afrancesado (D. Félix Amat, D. Vicente Román Gómez, D. Ramón José de Arce), Actas mesa redonda, Aix-en-Provence, 26 abril 1986, Etudes Hispaniques, $11,1987$.

(2) Jean Tulard, Alberto Gil Novales, Albert Dérozier, Lluis Roura Aulinas, Jacques Penot, Aline Vauchelle-Haquet, José Javier Sánchez Aranda, Jean-René Aymes, J. F. Fuentes, Rafael Olaechea, Geneviè Barbè-Coquelin de Lisle, Louis Trenard, Claudette Dérozier, Jeanne Battesti-Pelegrin, Nelly Clemessy, Emmanuel Larraz, Guy Mercadier, Joan Brines, A. Moliner, Gérard Dufour, José A. Ferrer Benimeli, Emilio La Parra, Enric Olivé, Anaclet Pons y Justo Serna presentaron comunicaciones a este Coloquio, que llegó a reunir cerca de 60 especialistas españoles y franceses.

(3) Los participantes en la mesa redonda fueron G. Dufour, José A. Ferrer Benimeli, Leandro Higueruela del Pino y Emilio La Parra López.

(4) Participaron en esta mesa redonda Leandro Higueruela, Maximiliano Barrio Gonzalo y Gérard Dufour. 